\title{
Effect of Lignin on the Mechanical Properties of a Composite Material Based on Date Palm Leaflets and Expanded Polystyrene Wastes
}

\author{
Tahar Masri $^{1}$, Houdayfa Ounis ${ }^{2,3^{*}}$, Adel Benchabane $^{1}$, Lakhdar Sedira $^{4}$ \\ ${ }^{1}$ Laboratoire de Génie Energétique et Matériaux, LGEM, Université de Biskra, B.P. 145, Biskra 07000, Algeria \\ ${ }^{2}$ Centre de Développement des Energies Renouvelables, CDER, Algiers 16340, Algeria \\ ${ }^{3}$ Institut de Recherche Dupuy de Lôme (IRDL), Université de Bretagne Sud, Centre National de la Recherche Scientifique, \\ FRE3744, France \\ ${ }^{4}$ Laboratoire de Génie Mécanique (LGM), Université de Biskra, B.P. 145, Biskra 07000, Algeria
}

Corresponding Author Email: houdayfa.ounis@gmail.com

https://doi.org/10.18280/ti-ijes.632-440

Received: 16 February 2019

Accepted: 23 April 2019

\section{Keywords:}

bio-composite, mechanical characterization, vegetal waste, industrial waste, low-cost, recycling

\begin{abstract}
This work presents an experimental study on a composite material obtained from vegetable and industrial wastes. The date palm leaflets waste was used as reinforcement in the form of short fibers, and the expanded polystyrene waste was recycled and used as a matrix for the preparation of the leaflets polystyrene composite material (LPC). The LPC material without lignin was prepared using a mass proportion of 70/30 \% between the reinforcement and the matrix. In order to evaluate the effect of the presence of lignin on the mechanical properties of the LPC material, three combinations between reinforcement, matrix and lignin are considered. The three mass proportions between the reinforcement, matrix and lignin are respectively (70/28.5/1.5\%), (70/27/3\%) and (27/26.5/4.5\%). Threepoint bending tests were carried out to obtain the mechanical properties both flexural modulus and maximum stress. A comparative study between the mechanical properties of the LPC material without lignin (Fibers/Matrix) and the composite material with the presence of the lignin (Fiber/Matrix/lignin) is carried out. Results have shown that the presence of lignin in the LPC material reduces the bending mechanical properties of the material.
\end{abstract}

\section{INTRODUCTION}

The Increasing in fossil energy costs and environmental conditions have created new aspects for the industrial production of biodegradable materials based on renewable natural resources [1]. In fact, environmental legislation and the high demand for building materials increase all the manufacturing requirements of these materials and final products in order to take into account the impact of products at all stages of their life cycle [2].

After several years, the development of synthetic fibers has dominated the field of manufacturing composite materials [3]. Due to the high cost and environmental impact of these types of composite, the use of lignocellulosics as a filler or reinforcement in the thermoplastic material has aroused renewed interest due to its environmentally friendly appearance [2, 4]. However, much work has been done on plant-based fibers, with potential to replace synthetic fibers [5].

The biodegradable nature of natural fibers can contribute to the health of an ecosystem while allowing them to compete [5]. The use of natural fibers gives advantages to composite materials that can be summarized as follows: a reduced specific weight, favorable to the process, and better use in thermal and acoustic insulation. However, some disadvantages, such as moisture absorption, limited maximum processing temperatures, lower durability, low fire resistance, and price fluctuation depending on the results of the harvest or agricultural policy can limit their industrial application [3].

In recent years, composite materials based on polymers reinforced with short natural fibers have been of great importance due to the advantages they confer on treatment and the low cost associated with high strength. The mechanical properties of fiber-reinforced composites depend on several factors such as fiber/matrix adhesion, fiber volume fraction, fiber length ratio, fiber orientation, and stress transfer efficiency of the interface [5].

Most of the research carried out on composite materials based on natural fibers deals with: identification and classification of fibers, size of crystalline fibrils and noncrystalline regions, crystalline and void structure, treatments and adaptations of natural fibers, study of compatible fiber/matrix composites [3].

The adhesion between the matrix and the fiber is an important parameter that affects the mechanical properties of the composite material, since a good adhesion between the fiber and the matrix ensures a good transfer of stress from the matrix to the fiber [1]. Furthermore, the compatibility between the lignocellulosic material and the polymeric matrix is a substantial factor in determining the properties of the composite material [6]. Moreover, the mechanical properties 
of the lignocellulosic composite material also depend on the chemical composition of the fibers which are mainly composed of cellulose, hemicellulose and lignin [1].

Sometimes, lignin is isolated as a powder, but most often, it exists as a gummy mixture that has a wide range of molecular weights [2]. Lignin is the polyphenolic aggregate located on fiber surface, may play a key role on the fiber/matrix chemical adhesion [1]. The effect of lignin content on the physical and mechanical properties of composites has been studied by Muensri et al. [1]. It has been reported that in the case where lignin has been removed, by chemical treatment, the mechanical properties of the bio composites have increased, suggesting that the lignin/lignocellulosic reinforcement ratio is an important parameter.

In this context, the present work aims to study the effect of date palm lignin on the mechanical properties of a composite material based on date palm waste and expanded polystyrene. Different weight ratios between reinforcement, matrix and lignin were considered and a comparative study is presented investigating the mechanical properties of the LPC material with and without lignin.

\section{MATERIALS AND METHODS}

\subsection{Materials}

\section{(1) Reinforcement}

This work presents a follow-up of the study realized by Masri et al. [7] on a composite based on the waste of date palm leaflets and expanded polystyrene (LPC). The reinforcement used for the elaboration of the material is obtained from the residues of the date palm leaves of the oasis of Biskra in Algeria. According to the reinforcement preparation procedure followed by Masri et al. [7]. Leaflets were cleaned with water to remove dust and impurities and then dried naturally for three days to reduce moisture content. After drying, the date palm leaflets are crushed and sieved. The reinforcement used in the elaboration of the LPC has a particle size between $0.315-0.5 \mathrm{~mm}$ (Figure 1). The lignin used in the present study is obtained from the shredded date palm leaves where a particle size less than $0.1 \mathrm{~mm}$ is used.

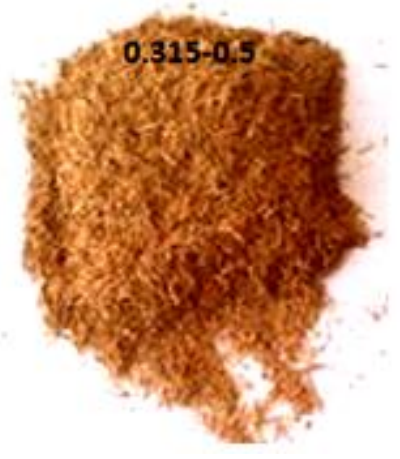

Figure 1. Leaflet fibers reinforcement

\section{(2) Matrix}

The matrix used in the elaboration of the LPC is obtained by dissolving expanded polystyrene waste in gasoline [7]. The expanded polystyrene used in the preparation of the matrix has a density of $15 \mathrm{Kg} / \mathrm{m}^{3}$.

(3) Preparation of test specimens
For the preparation of the LPC material, several mass fractions between reinforcement, matrix and lignin are considered (Table 1). The reinforcement is mixed with the matrix and lignin. Then, the mixture (Reinforcement/matrix/lignin) is poured into a metal mold to obtain plates of dimensions $240 \times 120 \times 10 \mathrm{~mm}^{3}$. As indicated in the literature [2], a holding pressure of 3.5 bar is applied for $10 \mathrm{~min}$ to ensure a good distribution of the mixture and to reduce the air in the LPC. After compression, the plates obtained are dried in air under ambient conditions for at least 15 days (Figure $2-a$ ). After drying, the plates are cut to obtain specimens with dimensions $\mathrm{l}=200 \mathrm{~mm}, \mathrm{~h}=10 \mathrm{~mm}$ and $\mathrm{b}=15$ $\mathrm{mm}$ (Figure 2-b) according to the standard EN ISO 14125 [3].

Table 1. The different samples studied

\begin{tabular}{cccc}
\hline & Reinforcement & Matrix & lignin \\
\hline LPC1 & $70 \%$ & $30 \%$ & $0 \%$ \\
\hline LPC2 & $70 \%$ & $28.5 \%$ & $1.5 \%$ \\
\hline LPC3 & $70 \%$ & $27 \%$ & $3 \%$ \\
\hline LPC4 & $70 \%$ & $25.5 \%$ & $4.5 \%$ \\
\hline
\end{tabular}
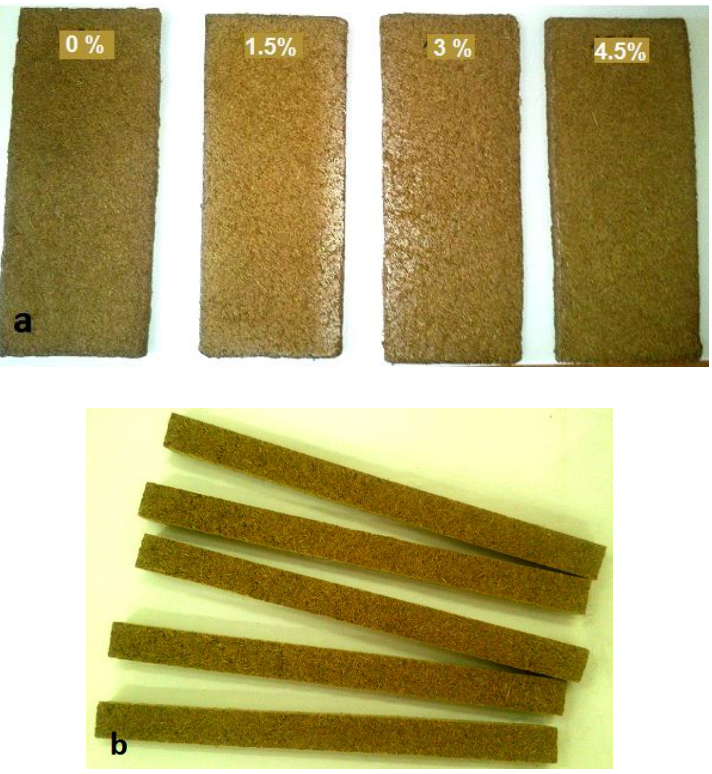

Figure 2. a) The plates of LPC Material, b) The specimens of bending tests

\subsection{Mechanical characterization method}

The determination of the mechanical properties was carried out using a universal testing machine, Model Instron 5567. Three-point bending tests were carried out on standardized specimens (Figure 3). The loading speed used in the test is 2 $\mathrm{mm} / \mathrm{min}$. In each case, five samples were tested in three-point bending in order to obtain the maximum stress $\sigma_{\text {Max }}$ and flexural modulus $\sigma_{f}$ of the LPC material.

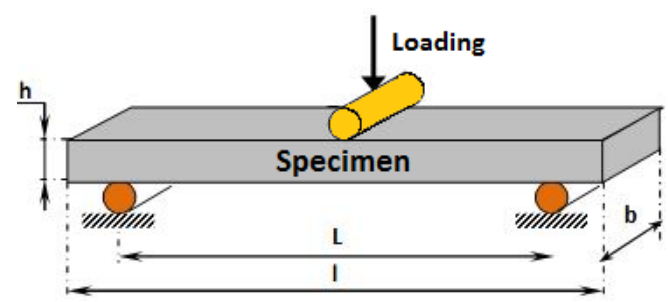

Figure 3. Three-point bending tests 


\section{RESULTS AND DISCUSSION}

Figure 4 shows Stress/strain curves of different samples studied. The Figure 4 shows the effect of lignin on the mechanical behavior of the LPC material. It is observed that the values of the slopes of the curve decrease with the increase of the amount of lignin and that the LPC material becomes more elastic. The material has a brittle fracture with the addition of $5 \%$ lignin in the LPC material. Beyond this value, the mechanism of rupture becomes ductile.

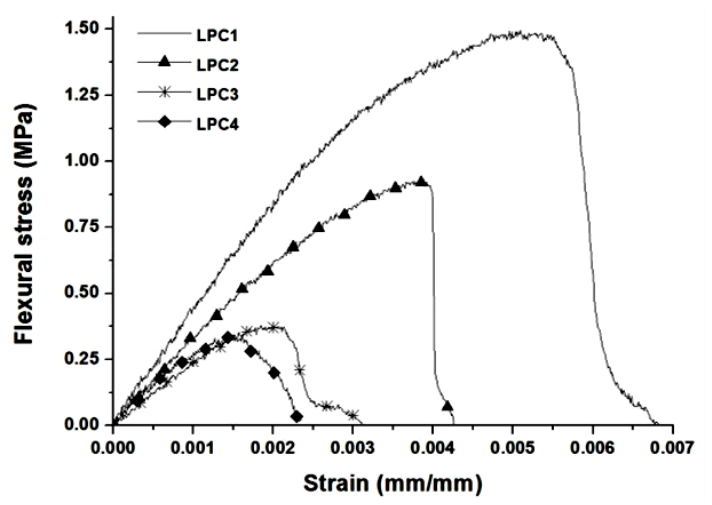

Figure 4. Stress/strain curves of different samples studied

Figures 5-a and 5-b respectively show the flexural modulus and the maximum stress for the different samples considered. It can be seen in figure 5-a that flexural modulus generally decreases with increasing the amount of lignin. The same observations have been noticed for the maximum stress presented in figure 5-b. These results show low standard deviations for flexural modulus (5\% to $12 \%$ ) and acceptable standard deviations for maximum stress (10\% to $30 \%)$.
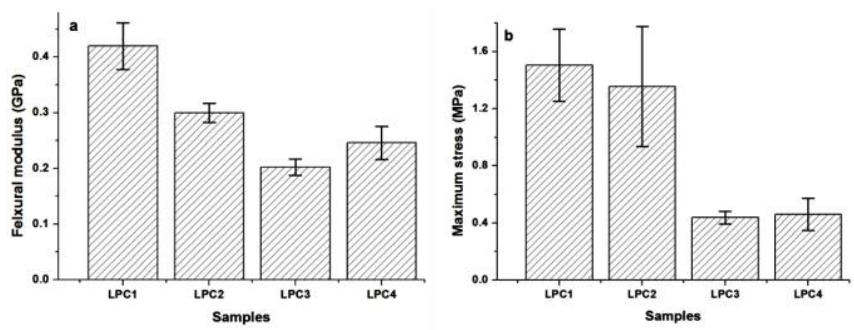

Figure 5. Mechanical properties of LPC material: a) Flexural modulus, b) Maximum stress

According to this study, the addition of lignin in the LPC material has an inverse effect on the mechanical properties of the material. The same observation has been reported by several researchers [4-7]. Rozman et al. [5] have observed a considerable reduction in resistance as the percentage of lignin increases. This reduction is due to the degree of compatibility at the level of the interfacial region between lignin and the matrix that is not desired. According to SEM results, Rozman et al. [11] have observed that lignin is loosely encrusted in the matrix and, in some cases, lignin particles are extracted from the matrix.

For the mechanical properties of the composite material, Rozman et al. have improved the compatibility between the lignin and the polypropylene (PP) matrix by adding a toluene diisocyanate (TDI) adhesive. The results showed that the TDImodified lignin had a higher tensile strength than the unmodified lignin-containing composite material.

\section{CONCLUSION}

This work presents an experimental study on a composite material obtained from vegetal and industrial waste. The date palm leaflet waste was used as short fiber reinforcement and the expanded polystyrene industrial waste was recycled and used as a matrix for the preparation of the polystyrene composite material (LPC). In this study the effect of the presence of lignin on the mechanical properties of the LPC material is investigated. The mechanical properties of the LPC material, flexural modulus and maximum stress were determined from the three-point bending tests. The comparative study between the mechanical properties of lignin-free LPC material (Fibers/Matrix) and the composite material with the presence of lignin (Fiber/Matrix/lignin) has shown that the presence of lignin reduces the bending properties of the LPC material.

\section{REFERENCES}

[1] Muensri P, Kunanopparat T, Menut P, Siriwattanayotin S. (2011). Effect of lignin removal on the properties of coconut coir fiber/wheat gluten biocomposite. Composites Part A: Applied Science and Manufacturing 42(2): 173-179. https://doi.org/10.1016/j.compositesa.2010.11.002

[2] Biagiotti J, Puglia D, Kenny JM. (2004). A review on natural fibre-based composites-part I: structure, processing and properties of vegetable fibres. Journal of $\begin{array}{lll}\text { Natural } & \text { Fibers } & \text { 1(2): }\end{array}$ https://doi.org/10.1300/J395v01n02 04

[3] Puglia D, Biagiotti J, Kenny J. (2005). A review on natural fibre-based composites-Part II: Application of natural reinforcements in composite materials for automotive industry. Journal of Natural Fibers 1(3): 2365. https://doi.org/10.1300/J395v01n03_03

[4] Toriz G, Denes F, Young R. (2002). Ligninpolypropylene composites. Part 1: Composites from unmodified lignin and polypropylene. Polymer Composites 23(5): 806-813.

[5] Joseph P, Joseph K, Thomas S. (1999). Effect of processing variables on the mechanical properties of sisal-fiber-reinforced polypropylene composites. Composites science and Technology 59(11): 1625-1640. https://doi.org/10.1016/S0266-3538(99)00024-X

[6] Rozman HD, Tan KW, Kumar RN, Abubakar A, Ishak ZAM, Ismail H. (2000). The effect of lignin as a compatibilizer on the physical properties of coconut fiber-polypropylene composites. European Polymer Journal 36(7): 1483-1494. https://doi.org/10.1016/S0014-3057(99)00200-1

[7] Masri T, Ounis H, Sedira L, Kaci A, Benchabane A. (2018). Characterization of new composite material based on date palm leaflets and expanded polystyrene wastes. Construction and Building Materials 164: 410418. https://doi.org/10.1016/j.conbuildmat.2017.12.197

[8] Dhakal H, Zhang Z, Richardson M. (2007). Effect of water absorption on the mechanical properties of hemp fibre reinforced unsaturated polyester composites. Composites science and Technology 67(7-8): 1674-1683. https://doi.org/10.1016/j.compscitech.2006.06.019

[9] ISO N. (1998). 14125, «. Composites plastiques renforcés de fibres-Détermination des propriétés de 
flexion.

[10] Alexy P, Košsková B, Podstránska G. (2000). The effect of blending lignin with polyethylene and polypropylene on physical properties. Polymer 41(13): 4901-4908. https://doi.org/10.1016/S0032-3861(99)00714-4

[11] Rozman H, Tan KW, Kumar RN, Abubakar A. (2001). Preliminary studies on the use of modified ALCELL lignin as a coupling agent in the biofiber composites. Journal of Applied Polymer Science 81(6): 1333-1340. https://doi.org/10.1002/app.1558

[12] Thielemans W, Can E, Morye SS, Wool RP. (2002). Novel applications of lignin in composite materials. Journal of Applied Polymer Science 83(2): 323-331. https://doi.org/10.1002/app.2247 